\title{
EFEITOS DOS EXTRATIVOS E CINZAS NA RESISTÊNCIA NATURAL DE QUATRO MADEIRAS A CUPINS XILÓFAGOS
}

\author{
Juarez Benigno Paes ${ }^{1 *}$, Pedro Nicó de Medeiros Neto' ${ }^{1}$ Carlos Roberto de Lima², \\ Maria de Fátima de Freitas², Carlos Estevam Franco Diniz ${ }^{2}$
}

*Autor para correspondência: jbp2@uol.com.br

\begin{abstract}
RESUMO: O objetivo da pesquisa foi correlacionar a resistência natural de quatro madeiras ao ataque do térmita xilófago Nasutitermes corniger Motsch. com a quantidade de extrativos e cinzas presentes na composição química das espécies ensaiadas. As madeiras avaliadas foram angico (Anadenanthera colubrina (Vell.) Brenan. var. cebil (Gris.) Alts.), craibeira (Tabebuia aurea (Mart.) Bureau.), cumaru (Amburana cearensis (Allem.) A.C.Sm.) e eucalipto (Eucalyptus camaldulensis Dehnh.). De cada espécie, foram retirados corpos de prova, com dimensões de 2,00 x 10,16 x 0,64 cm (radial x longitudinal x tangencial) em duas posições (cerne externo e alburno). As amostras ficaram expostas à ação dos cupins durante 45 dias em ensaio de preferência alimentar. O teor de extrativos das madeiras foi obtido por meio da serragem que passou pela peneira de 40 "mesh" e ficou retida na de 60 "mesh". A resistência natural não esteve associada aos teores de extrativos presentes na madeira. A madeira mais resistente ao ataque dos térmitas foi o angico nas duas posições avaliadas (cerne externo e alburno) e a madeira de eucalipto foi a que apresentou o maior desgaste, ocasionado pelos cupins. A resistência biológica das madeiras esteve correlacionada com o teor de cinzas, ou seja, a espécie que apresentou o maior teor de cinzas foi a mais resistente ao ataque dos térmitas.
\end{abstract}

Palavras-chave: Durabilidade natural, térmitas subterrâneos, preferência alimentar.

\section{EFFECTS OF EXTRACTIVES AND ASH ON NATURAL RESISTANCE OF FOUR WOODS TO XYLOPHOGOUS TERMITES}

\begin{abstract}
This study tested the natural resistance of wood of four tree species to Nasutitermes corniger Motsch. xylophogous termite attack and correlate the resistance with the amount of extract and ash in the chemical composition of the tested species. The species evaluated were Anadenanthera colubrina (Vell.) Brenan. var. cebil (Gris.) Alts., Tabebuia aurea (Mart.) Bureau., Amburana cearensis (Allem.) A.C.Sm. and Eucalyptus camaldulensis Dehnh. Test samples with dimensions of $2.00 \times 10.16 \times 0.64 \mathrm{~cm}$ (radial $x$ longitudinal $x$ tangential) were obtained at two positions (external heartwood and sapwood) of each species. The samples were exposed to action of termites for 45 days in food preference assay. The content of wood extractives was obtained through the sawdust that went through sieve of 40 mesh and were retained in the 60 mesh. The natural resistance was not associated with wood extractive contents. The wood more resistant to termite attack was the Anadenanthera colubrina var. cebil in the two positions (external heartwood and sapwood) and Eucalyptus camaldulensis wood presented the greatest wear. The biological resistance of wood was correlated with ash content, i.e., the species with the highest levels was the most resistant to termite attack.
\end{abstract}

Key words: Natural durability, subterranean termites, food preference assay.

\section{INTRODUÇÃO}

Os vegetais lenhosos têm sido empregados para diversos fins, sendo uma das fontes mais utilizadas para produção de energia, celulose e papel, material de construção para os meios urbano e rural, produtos para fins medicinais, entre outros, evidenciando assim sua importância como material renovável e mais acessível que as outras fontes de matéria prima.

A madeira é constituída por celulose, lignina e hemicelulose e por diversos compostos denominados de extrativos. Os extrativos são componentes que não fazem parte da constituição química da parede celular e inclui elevado número de compostos, como resinas, açúcares, taninos, ácidos graxos, dentre outros, que podem ser extraídos em água ou solventes orgânicos (SILVÉRIO et al., 2006).

Segundo Oliveira et al. (2005), uma das principais características das madeiras é a sua maior ou menor suscetibilidade de ser atacada por organismos xilófagos. Os extrativos são os responsáveis pela cor, odor e resistência ao apodrecimento e ao ataque de insetos. Além disto, influenciam as propriedades da madeira como permeabilidade, densidade e dureza (PETTERSEN, 1984).

Apesar da diversidade de espécies, a vegetação de Caatinga é pouco conhecida no meio científico, tornandose evidente a necessidade de informações relativas às características energéticas, químicas, físico-mecânicas da

${ }^{1}$ Universidade Federal do Espírito Santo - Jerônimo Monteiro, Espírito Santo, Brasil

${ }^{2}$ Universidade Federal de Campina Grande - Patos, Paraíba, Brasil

Cerne, Lavras, v. 19, n. 3, p. 399-405, jul./set. 2013 
madeira e o efeito dos extrativos na resistência natural das madeiras a fungos e térmitas (cupins) xilófagos.

A madeira de angico (Anadenanthera colubrina var. cebil) é empregada na construção civil e no meio rural, em moirões de cerca, porteiras e para fins energétivcos. A casca do angico é utilizada na indústria de curtumes tradicionais da Região Nordeste. A craibeira (Tabebuia aurea) é utilizada na construção civil (fabricação de portas, janelas e batentes) e na confecção de ferramentas e móveis. O cumaru (Amburana cearensis) é empregado na construção civil (portas e janelas), móveis finos e pisos. O eucalipto (Eucalyptus camaldulensis) foi plantado na região litorânea do Estado da Paraíba com a finalidade energética e madeira para escoramentos e cercas.

As características edafoclimáticas do semiárido brasileiro favorecem o desenvolvimento de cupins xilófagos. Isso pode ser observado em virtude do ataque desses insetos às madeiras empregadas em obras e em estruturas diversas (PAES et al., 2003, 2007). Os cupins do gênero Nasutitermes são aqueles que apresentam a maior distribuição na região semiárida, atacando, com frequência, madeira empregada nos meios rural e urbano.

Em geral, há variação na resistência natural entre o cerne interno e o externo. Para as espécies em que tal variação ocorre, a madeira proveniente da porção interna do cerne, formada quando a planta era jovem, é menos resistente à decomposição que a proveniente do cerne externo, região fronteiriça com o alburno, formada pela planta mais madura. Porém, nem todas as espécies apresentam esse padrão de variação e, em algumas, a região próxima à medula é tão resistente quanto à região externa do cerne, enquanto a madeira de alburno é suscetível à deterioração biológica (FINDLAY, 1985; PANSHIN; ZEEUW, 1980; SCHEFFER, 1973).

Em virtude da utilização da madeira para diversos fins, é de suma importância o conhecimento de sua resistência natural ao ataque de organismos xilófagos, uma vez que a utilização inadequada de madeiras que apresentam uma baixa resistência natural a organismos xilófagos promoverá um maior custo em virtude da baixa vida útil do material, necessitando de reposições e, consequentemente, de uma maior exploração dos recursos florestais.

Em função da importância dos extrativos na resistência das madeiras a organismos xilófagos, esta pesquisa teve como objetivos relacionar a resistência natural ao térmita xilófago Nasutitermes corniger Motsch. das madeiras de angico (Anadenanthera colubrina var. cebil), craibeira (Tabebuia aurea), cumaru (Amburana cearensis) e eucalipto (Eucalyptus camaldulensis) com a quantidade de extrativos e cinzas presentes nas madeiras de cerne externo e alburno das espécies estudadas.

\section{MATERIAL E MÉTODOS}

\subsection{Espécies estudadas}

Nesta pesquisa, foram estudadas quatro espécies florestais, sendo três de ocorrência natural na Caatinga: angico (Anadenanthera colubrina (Vell.) Brenan. var. cebil (Gris.) Alts.); craibeira (Tabebuia aurea (Mart.) Bureau.); cumaru (Amburana cearensis (Allem.) A.C.Sm.); e uma exótica: Eucalyptus camadulensis (Dehnh.).

\subsection{Coleta e preparo do material}

As madeiras estudadas foram adquiridas na Serraria Dois Irmãos, localizada na cidade de Patos, PB, com exceção do eucalipto que foi proveniente de plantios com quatro anos de idade, localizado no Município de Rio Tinto, $\mathrm{PB}$, cujas toras encontravam-se na Marcenaria do Centro de Saúde e Tecnologia Rural (CSTR) da Universidade Federal de Campina Grande (UFCG), Campus de Patos.

Das peças obtidas, foram utilizados toretes de aproximadamente $40 \mathrm{~cm}$ de comprimento com diâmetros variando de 25 a $30 \mathrm{~cm}$, contendo o alburno e o cerne intactos. Dos toretes foram obtidos corpos de prova, com dimensões de 2,00 x 10,16 x 0,64 cm (radial x longitudinal x tangencial), provenientes do alburno e cerne externo (região fronteiriça com o alburno).

Para o ensaio com os térmitas (cupins) da espécie Nasutitermes corniger Motsch. foram utilizados 10 corpos de prova para cada posição, totalizando 20 amostras de cada espécie estudada. As amostras foram lixadas para eliminar defeitos e secas em estufa a temperatura de $103 \pm$ $2{ }^{\circ} \mathrm{C}$, até atingirem massas constantes, e pesadas em uma balança de $0,01 \mathrm{~g}$ de precisão.

As amostras, não selecionadas para o ensaio com cupins, foram transformadas em cavacos, com dimensões semelhantes a palitos de fósforos, e transformada em serragem em moinho do tipo Willey. A serragem obtida foi peneirada e utilizou-se a que passou pela peneira de 40 e ficou retida na de 60 "mesh". A serragem, após ser classificada, foi acondicionada a uma umidade relativa de $65 \pm 5 \%$ e temperatura de $25 \pm 2{ }^{\circ} \mathrm{C}$ até massa constante e, destinada, posteriormente, à determinação do teor de extrativos e cinzas presentes nas madeiras.

\subsection{Ensaio de preferência alimentar}

Na montagem do ensaio, os corpos de prova ficaram dispostos em uma caixa com capacidade de 250 litros,

Cerne, Lavras, v. 19, n. 3, p. 399-405, jul./set. 2013 
contendo uma camada de $\pm 10 \mathrm{~cm}$ de areia úmida. A caixa foi apoiada sobre três blocos cerâmicos colocado em bandejas de plástico de $26 \times 35 \times 4,5 \mathrm{~cm}$, contendo água para evitar a fuga dos cupins, conforme metodologia descrita por Paes et al. (2007).

As amostras foram fixadas, tendo a metade do seu comprimento soterrado na areia, e distribuídas em delineamento em blocos casualisados com arranjo fatorial, com dez blocos (repetições), duas posições no tronco e quatro tratamentos (espécies), mantendo um espaçamento de 4,5 cm (entre blocos) e 6,0 cm (entre amostras).

A colônia de Nasutitermes corniger foi coletada nas proximidades do Laboratório de Tecnologia de Produtos Florestais (LTPF) da UFCG, Campus de Patos, PB, e disposta sobre uma grelha de 30 x $40 \mathrm{~cm}$, sustentada por dois tijolos de oito furos apoiados sobre a camada de areia presente na caixa.

As amostras ficaram expostas à ação dos cupins durante 45 dias, em uma sala climatizada $\left(27 \pm 2{ }^{\circ} \mathrm{C}\right.$ e $70 \pm$ $5 \%$ de umidade relativa). Após o término do ensaio as amostras foram limpas com uma escova de cerdas macias para retirar o excesso de areia e secas em estufa a $103 \pm 2{ }^{\circ} \mathrm{C}$ até atingirem massas constantes e determinados a perda de massa e o desgaste (nota) sofridos em função da atividade biológica, segundo as normas da American Society for Testing and Materials - ASTM (2005) (Tabela 1).

Tabela 1 - Avaliação do desgaste provocado pelos cupins nos corpos de prova (ASTM, 2005).

Table 1 - Waste evaluation caused by termites in the samples (ASTM, 2005).

\begin{tabular}{lc}
\hline Tipos de desgaste & Nota \\
\hline Sadio, permitindo escarificações superficiais & 10 \\
Ataque superficial & 9 \\
Ataque moderado, havendo penetração & 7 \\
Ataque intensivo & 4 \\
Falha, havendo ruptura dos corpos-de-prova & 0 \\
\hline
\end{tabular}

\subsection{Determinação do teor de extrativos}

A solubilidade da madeira em álcool:tolueno, álcool, água quente, água fria e o teor de cinzas foram efetuados, segundo as normas da ASTM (2005), ao substituir o benzeno pelo tolueno, com a utilização do extrator tipo Soxhlet. As análises químicas para a determinação dos extrativos foram realizadas em duplicatas.
Ao término de cada extração, os balões previamente tarados foram colocados em estufa à temperatura de $103 \pm$ $2{ }^{\circ} \mathrm{C}$, até atingirem massa constante, e pesados em uma balança de $0,001 \mathrm{~g}$ de precisão. Após essa etapa foi determinado o teor de extrativos.

\subsection{Avaliação dos resultados}

O teor de extrativos das madeiras nas posições estudadas (cerne externo e alburno) foi avaliado ao empregar um delineamento inteiramente casualizado com arranjo fatorial em que foram analisados os efeitos dos fatores madeira, posição na direção medula-casca e a interação entre os fatores.

Para comparar a resistência das madeiras, além dos valores apresentados na Tabela 2, foi empregado o delineamento em blocos casualizados, com arranjo fatorial, em que foram analisados os efeitos dos fatores: madeira, posição na direção medula-casca e a interação entre os fatores.

Para possibilitar a análise estatística, os dados de perda de massa e cinzas foram transformados em: $\operatorname{arcsen} \sqrt{\frac{x}{100}}$; e os do desgaste em: $\sqrt{\frac{\text { nota }}{0,5}}$. Essas transformações, sugeridas por Steel e Torrie (1980), foram necessárias para permitir a homogeneidade das variâncias. Na análise e avaliação dos ensaios, foi empregado o teste de Tukey $(\mathrm{p} \leq 0,05)$, para os fatores e interações detectados como significativos pelo teste de $\mathrm{F}(\mathrm{p} \leq 0,05)$. Para analisar o efeito dos extrativos e cinzas na resistência das madeiras, foi empregada a correlação de Pearson e teste de $\mathrm{t}(\mathrm{p} \leq 0,05)$.

\section{RESULTADOS E DISCUSSÃO}

Os valores médios da perda de massa (\%) e desgaste (nota) sofrido pelas amostras em função do ataque dos térmitas, o teor de cinzas na madeira (\%) e os teores de extrativos (\%) obtidos para as espécies ensaiadas encontram-se na Tabela 2.

Observa-se, na Tabela 2, que a perda de massa, o desgaste, o teor de cinzas e os teores de extrativos, obtidos com os extratores empregados variaram entre e dentre as espécies estudadas. Os valores de resistência natural a cupins, expressos pela perda de massa e pelo desgaste sofrido pelas madeiras podem estar relacionados com o teor de cinzas e extrativos presentes na sua composição química. Para verificar o efeito dos teores de extrativos e cinzas na resistência natural das madeiras a cupins, empregou-se a correlação de Pearson (Tabela 3).

Cerne, Lavras, v. 19, n. 3, p. 399-405, jul./set. 2013 
Tabela 2 - Valores médios da perda de massa (\%), desgaste (nota), teor de cinzas (\%) e os teores de extrativos (\%) obtidos das espécies ensaiadas.

Table 2 - Average values of woody mass loss (\%), waste, ash content (\%) and extractive contents (\%) obtained of assayed species.

\begin{tabular}{|c|c|c|c|c|c|c|c|c|c|}
\hline \multirow{3}{*}{ Espécies } & \multirow{3}{*}{ Posições } & \multirow{3}{*}{$\begin{array}{c}\text { Perda de } \\
\text { Massa (\%) }\end{array}$} & \multirow{3}{*}{$\begin{array}{c}\text { Desgaste } \\
\text { (Nota) }\end{array}$} & \multirow{3}{*}{$\begin{array}{c}\text { Cinzas } \\
(\%)\end{array}$} & \multicolumn{5}{|c|}{ Teores de Extrativos (\%) } \\
\hline & & & & & \multicolumn{2}{|c|}{ Água } & \multirow{2}{*}{ Álcool } & \multirow{2}{*}{$\begin{array}{l}\text { Álcool } \\
\text { Tolueno }\end{array}$} & \multirow{2}{*}{ Totais } \\
\hline & & & & & Fria & Quente & & & \\
\hline \multirow{2}{*}{ Angico } & Alburno & 0,90 & 9,52 & 2,48 & 4,65 & 8,53 & 9,17 & 8,85 & 9,66 \\
\hline & Cerne & 0,77 & 9,74 & 2,53 & 5,70 & 9,50 & 9,30 & 8,88 & 9,86 \\
\hline \multirow{2}{*}{ Craibeira } & Alburno & 15,01 & 5,14 & 0,68 & 2,03 & 3,55 & 3,30 & 2,13 & 2,79 \\
\hline & Cerne & 15,86 & 4,38 & 0,70 & 2,15 & 4,33 & 12,45 & 12,60 & 14,74 \\
\hline \multirow{2}{*}{ Cumaru } & Alburno & 50,77 & 1,26 & 1,93 & 8,75 & 12,15 & 8,92 & 7,48 & 8,58 \\
\hline & Cerne & 17,54 & 5,84 & 2,18 & 8,42 & 12,45 & 12,55 & 12,30 & 13,59 \\
\hline \multirow{2}{*}{ Eucalipto } & Alburno & 100,00 & 0,00 & 0,30 & 2,53 & 3,95 & 5,65 & 3,35 & 4,10 \\
\hline & Cerne & 96,25 & 0,00 & 0,35 & 3,05 & 5,44 & 6,30 & 4,98 & 5,76 \\
\hline
\end{tabular}

Tabela 3 - Correlações entre perda de massa (\%) e desgaste (nota) x teores de cinzas e extrativos nas madeiras.

Table 3 - Correlations among woody mass loss (\%) and waste $x$ ash content and extractives in woods.

\begin{tabular}{|c|c|c|c|c|c|c|c|}
\hline \multirow{3}{*}{ Parâmetros } & \multirow{3}{*}{ Posições } & \multirow{3}{*}{$\begin{array}{c}\text { Cinzas } \\
(\%)\end{array}$} & \multicolumn{5}{|c|}{ Teores de Extrativo (\%) } \\
\hline & & & \multicolumn{2}{|c|}{ Água } & \multirow{2}{*}{ Álcool } & \multirow{2}{*}{$\begin{array}{l}\text { Álcool } \\
\text { Tolueno }\end{array}$} & \multirow{2}{*}{ Totais } \\
\hline & & & Fria & Quente & & & \\
\hline \multirow{2}{*}{ Perda de massa (\%) } & Alburno & $-0,62$ ns & $-0,04^{\mathrm{ns}}$ & $-0,19^{\mathrm{ns}}$ & $-0,14^{\mathrm{ns}}$ & $-0,36^{\mathrm{ns}}$ & $-0,34^{\mathrm{ns}}$ \\
\hline & Cerne & $-0,74^{\mathrm{ns}}$ & $-0,41^{\mathrm{ns}}$ & $-0,45^{\mathrm{ns}}$ & $-0,76^{\mathrm{ns}}$ & $-0,79^{\mathrm{ns}}$ & $-0,76^{\mathrm{ns}}$ \\
\hline \multirow{2}{*}{ Desgaste (Nota) } & Alburno & $0,61^{\mathrm{ns}}$ & $-0,15^{\mathrm{ns}}$ & $0,05^{\mathrm{ns}}$ & $0,22^{\mathrm{ns}}$ & $0,43^{\mathrm{ns}}$ & $0,40^{\mathrm{ns}}$ \\
\hline & Cerne & $0,90 *$ & $0,52^{\text {ns }}$ & $0,57^{\mathrm{ns}}$ & $0,44^{\mathrm{ns}}$ & $0,47^{\mathrm{ns}}$ & $0,42^{\mathrm{ns}}$ \\
\hline Perda de massa (\%) & & $-0,68 *$ & $-0,22^{\mathrm{ns}}$ & $-0,32^{\text {ns }}$ & $-0,44^{\text {ns }}$ & $-0,54^{\mathrm{ns}}$ & $-0,52^{\text {ns }}$ \\
\hline Desgaste (Nota) & & $0,75^{*}$ & $0,17^{\text {ns }}$ & $0,30^{\mathrm{ns}}$ & $0,35^{\text {ns }}$ & $0,44^{\mathrm{ns}}$ & $0,41^{\mathrm{ns}}$ \\
\hline
\end{tabular}

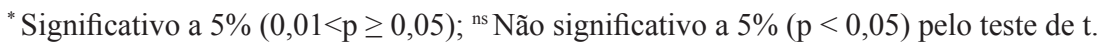

Nota-se (Tabela 3) que não houve correlação significativa a $5 \%$ de probabilidade entre os valores de resistência biológica da madeira (perda de massa e desgaste) e os teores de extrativos obtidos. No entanto, com relação ao teor de cinzas, observou-se correlação significativa e positiva a $5 \%$ de probabilidade para o desgaste ocorrido nas amostras advindas do cerne das espécies estudadas. Quando não se considerou o efeito da posição, houve correlação significativa e negativa para a perda de massa e positiva para o desgaste. Esses resultados, indicam que à proporção que aumenta o teor de cinza há uma redução do ataque dos cupins na madeira. Isso pode ter ocorrido em função da dificuldade dos cupins escarificarem madeira com maiores teores de cinzas (substâncias abrasivas), que podem danificar suas mandíbulas, reduzindo seu potencial de ataque.

Cerne, Lavras, v. 19, n. 3, p. 399-405, jul./set. 2013
As substâncias extraídas em água (quente ou fria), álcool absoluto, na solução álcool:tolueno e os extrativos totais não apresentaram correlação significativa com a resistência natural das madeiras ensaiadas ao cupim xilófago Nasutitermes corniger. Correlação significativa foi observada apenas para o teor de cinzas nas madeiras.

As análises de variância empregadas para comparar os valores de extrativos obtidos com os extratores utilizados indicaram que houve efeito significativo, para os fatores posição e espécie e para a interação entre esses fatores, para todos os extratores utilizados, indicando que as espécies apresentaram diferenças significativas entre os teores de extrativos de acordo com a posição na madeira e extrator utilizado. As interações foram desdobradas e analisadas pelo teste de Tukey, a 5\% de probabilidade (Tabela 4). 
Tabela 4 - Comparações entre médias dos extratores para as posições e espécies.

Table 4 - Comparisons among averages of extractors by the wood positions and by tree species.

\begin{tabular}{|c|c|c|c|c|}
\hline \multicolumn{5}{|c|}{ Teor de extrativos em água fria (\%) } \\
\hline \multirow{2}{*}{$\begin{array}{l}\text { Posições } \\
\text { analisadas }\end{array}$} & \multicolumn{4}{|c|}{ Espécies estudadas } \\
\hline & Angico & Craibeira & Cumaru & Eucalipto \\
\hline Alburno & $4,65 \mathrm{Ba}$ & $2,03 \mathrm{Ca}$ & $8,75 \mathrm{Aa}$ & $2,53 \mathrm{Ca}$ \\
\hline Cerne & $5,70 \mathrm{Bb}$ & $2,15 \mathrm{Da}$ & $8,42 \mathrm{Aa}$ & $3,05 \mathrm{Ca}$ \\
\hline \multicolumn{5}{|c|}{ Teor de extrativos em água quente (\%) } \\
\hline \multirow{2}{*}{$\begin{array}{l}\text { Posições } \\
\text { analisadas }\end{array}$} & \multicolumn{4}{|c|}{ Espécies estudadas } \\
\hline & Angico & Craibeira & Cumaru & Eucalipto \\
\hline Alburno & $8,53 \mathrm{Bb}$ & $3,55 \mathrm{Cb}$ & $12,15 \mathrm{Aa}$ & $3,95 \mathrm{Cb}$ \\
\hline Cerne & $9,50 \mathrm{Ba}$ & $4,33 \mathrm{Da}$ & $12,45 \mathrm{Aa}$ & $5,44 \mathrm{Ca}$ \\
\hline \multicolumn{5}{|c|}{ Teor de extrativos em álcool (\%) } \\
\hline \multirow{2}{*}{$\begin{array}{l}\text { Posições } \\
\text { analisadas }\end{array}$} & \multicolumn{4}{|c|}{ Espécies estudadas } \\
\hline & Angico & Craibeira & Cumaru & Eucalipto \\
\hline Alburno & 9,17 Aa & $3,30 \mathrm{Cb}$ & $8,92 \mathrm{Ab}$ & $5,65 \mathrm{Ba}$ \\
\hline Cerne & $9,30 \mathrm{Ba}$ & $12,48 \mathrm{Aa}$ & $12,55 \mathrm{Aa}$ & $6,30 \mathrm{Ca}$ \\
\hline \multicolumn{5}{|c|}{ Teor de extrativos em álcool:tolueno (\%) } \\
\hline \multirow{2}{*}{$\begin{array}{l}\text { Posições } \\
\text { analisadas }\end{array}$} & \multicolumn{4}{|c|}{ Espécies estudadas } \\
\hline & Angico & Craibeira & Cumaru & Eucalipto \\
\hline Alburno & $8,85 \mathrm{Aa}$ & $2,13 \mathrm{Db}$ & $7,48 \mathrm{Bb}$ & $3,35 \mathrm{Cb}$ \\
\hline Cerne & $8,88 \mathrm{Ba}$ & $12,90 \mathrm{Aa}$ & $12,30 \mathrm{Aa}$ & $4,98 \mathrm{Ca}$ \\
\hline \multicolumn{5}{|c|}{ Teor de extrativos totais $(\%)$} \\
\hline \multirow{2}{*}{$\begin{array}{l}\text { Posições } \\
\text { analisadas }\end{array}$} & \multicolumn{4}{|c|}{ Espécies estudadas } \\
\hline & Angico & Craibeira & Cumaru & Eucalipto \\
\hline Alburno & $9,66 \mathrm{Aa}$ & $2,79 \mathrm{Cb}$ & $8,58 \mathrm{Ab}$ & $4,10 \mathrm{Bb}$ \\
\hline Cerne & $9,86 \mathrm{Ba}$ & $14,74 \mathrm{Aa}$ & $13,59 \mathrm{Aa}$ & $5,76 \mathrm{Ca}$ \\
\hline
\end{tabular}

As médias seguidas por uma mesma letra maiúscula, na horizontal ou minúscula, na vertical, em cada seção, não diferem entre si (Tukey; $p \geq 0,05$ ).

Quanto à quantidade de substâncias extraídas das madeiras (Tabela 4), a água fria extraiu uma maior quantidade de substâncias presentes no cerne das espécies, com exceção para o cumaru, em que o teor de extrativos foi maior, numericamente, no alburno. Sendo esta a espécie com os maiores teores de extrativos presentes, seguido pelo angico, tendo a craibeira e o eucalipto os menores teores. Segundo Oliveira et al. (2005), a água fria extrai componentes como taninos, açúcares e corantes.
A água quente extraiu uma maior quantidade de substâncias do cerne das espécies, com exceção para o cumaru, em que os teores de extrativos foram semelhantes para o cerne e alburno (Tabela 4). Com relação às posições analisadas, o cumaru foi à espécie com o maior teor de extrativos extraídos do cerne e do alburno, seguido pelo angico, tendo a craibeira e o eucalipto apresentado os menores valores. De acordo com Oliveira et al. (2005), a água quente extrai as mesmas substâncias que a água fria, além de amido.

O álcool extraiu uma maior quantidade de substâncias presentes no cerne das espécies, com exceção do angico e do eucalipto, em que os teores de extrativos foram semelhantes (Tabela 4). Em relação ao cerne, o cumaru e a craibeira foram as espécies que apresentaram os maiores teores de extrativos e, o eucalipto, o menor teor. Para o alburno, as espécies com os maiores teores de extrativos foram o angico e o cumaru. A craibeira apresentou o menor teor.

O álcool-tolueno extraiu uma maior quantidade de substâncias presentes no cerne das espécies, com exceção do angico, em que o teor de extrativos foi semelhante (Tabela 4). Em relação ao cerne, a craibeira e o cumaru foram as espécies com os maiores teores de extrativos, e o eucalipto com o menor teor. Para o alburno, o angico foi a espécie com o maior teor de extrativos, e a craibeira o menor teor. Segundo Oliveira et al. (2005), a mistura etanol: tolueno na proporção 2:1 extrai cera, gorduras, resinas e óleos.

O teor de extrativos totais foi maior no cerne das espécies, exceção feita para o angico, em que o teor de extrativos entre o cerne e o alburno foi semelhante (Tabela 4). Com relação às espécies, o angico e o cumaru, apresentaram os maiores teores de extrativos no alburno e as espécies craibeira e cumaru no cerne.

Os valores de extrativos encontrados para a Anadenanthera colubrima var. cebil em água fria, álcool:tolueno e extrativos totais foram semelhantes aos apresentados por Mori et al. (2003), para a espécie Anadenanthera peregrina, que apresentou 6,56\% de extrativos em água fria, 8,72\% em álcool:tolueno e 12,09\% para o teor de extrativos totais.

As análises de variâncias para comparar o efeito da perda de massa e do desgaste, resultantes do ataque dos térmitas as madeiras ensaiadas e o teor de cinzas obtidas das espécies avaliadas indicaram que houve efeito significativo, para os fatores espécies, posição e para a interação entre posição e espécie, para a perda de massa

Cerne, Lavras, v. 19, n. 3, p. 399-405, jul./set. 2013 
e o desgaste sofrido pelos corpos de prova. Já, para o teor de cinzas, nota-se que houve efeito significativo apenas para a variável espécie. A interação dos fatores posição e espécie (perda de massa e desgaste) foi desdobrada e, juntamente com o teor de cinzas, analisadas pelo teste de Tukey a 5\% de probabilidade (Tabela 5).

Tabela 5 - Comparações entre médias da perda de massa (\%), do desgaste (nota) e do teor de cinzas para as posições e espécies analisadas.

Table 5-Comparisons among averages of woody mass loss (\%), waste and ash contents by the wood positions and by tree species.

\begin{tabular}{|c|c|c|c|c|}
\hline \multicolumn{5}{|c|}{ Teor de cinzas $(\%)$} \\
\hline \multicolumn{5}{|c|}{ Espécies estudadas } \\
\hline & Angico & Craibeira & Cumaru & Eucalipto \\
\hline & $2,50 \mathrm{~A}$ & $0,69 \mathrm{C}$ & $2,05 \mathrm{~B}$ & $0,33 \mathrm{D}$ \\
\hline \multicolumn{5}{|c|}{ Perda de massa (\%) } \\
\hline \multirow{2}{*}{$\begin{array}{l}\text { Posições } \\
\text { analisadas }\end{array}$} & \multicolumn{4}{|c|}{ Espécies estudadas } \\
\hline & Angico & Craibeira & Cumaru & Eucalipto \\
\hline Alburno & $0,90 \mathrm{Da}$ & $15,01 \mathrm{Ca}$ & $50,77 \mathrm{Ba}$ & $100,00 \mathrm{Aa}$ \\
\hline Cerne & $0,77 \mathrm{Ca}$ & $15,86 \mathrm{Ba}$ & $17,54 \mathrm{Bb}$ & $96,25 \mathrm{Aa}$ \\
\hline \multicolumn{5}{|c|}{ Desgaste (nota) } \\
\hline \multirow{2}{*}{$\begin{array}{l}\text { Posições } \\
\text { analisadas }\end{array}$} & \multicolumn{4}{|c|}{ Espécies estudadas } \\
\hline & Angico & Craibeira & Cumaru & Eucalipto \\
\hline Alburno & $9,52 \mathrm{Aa}$ & $5,14 \mathrm{Ba}$ & $1,26 \mathrm{Ca}$ & $0,00 \mathrm{Ca}$ \\
\hline Cerne & $9,74 \mathrm{Aa}$ & $4,38 \mathrm{Ca}$ & $5,84 \mathrm{Bb}$ & $0,00 \mathrm{Da}$ \\
\hline
\end{tabular}

As médias seguidas por uma mesma letra maiúscula, na horizontal ou minúscula, na vertical, em cada seção, não diferem entre si (Tukey; $p \geq 0,05$ ).

Observa-se que o teor de cinzas na madeira das espécies avaliadas (Tabela 5) foi maior no angico, seguido pelo cumaru e menor no eucalipto e depois na craibeira. Já, com relação à perda de massa das madeiras, observa-se que a madeira de angico apresentou a menor perda de massa, enquanto o eucalipto foi a menos resistente, tanto para as amostras de alburno quanto para as de cerne.

Com relação ao desgaste, observou-se que os térmitas provocaram escarificações e ataque superficial nos corpos de prova da madeira de angico (cerne externo e alburno). Nas madeiras de cumaru e craibeira o ataque foi intenso. Porém, no cumaru, o cerne foi menos atacado que o alburno. Dentre as madeiras estudadas eucalipto foi a mais atacada, tendo os cupins consumidos totalmente os corpos de prova durante o ensaio.

Cerne, Lavras, v. 19, n. 3, p. 399-405, jul./set. 2013
Paes et al. (2001), ao trabalharem com nove madeiras do Semiárido brasileiro, verificaram que a madeira de angico apresentou maior resistência ao ataque de cupins que as madeiras de cumaru e craibeira. Porém, os autores observaram diferenças de resistência entre as amostras oriundas do cerne e aquelas do alburno para as madeiras de angico, craibeira e cumaru. Neste estudo, não houve diferença significativa entre a resistência a cupins xilófagos das amostras de cerne e alburno de craibeira. Comportamento semelhante ocorreu para as amostras de cumaru obtidas do cerne e do alburno, quanto à resistência biológica, sendo este resultado diferente dos encontrados por Paes et al. (2001).

\section{CONCLUSÕES}

A resistência natural das madeiras testadas ao térmita Nasutitermes corniger não está relacionada com a quantidade de substâncias extraídas em água fria ou quente, álcool, álcool: tolueno e extrativos totais.

De modo geral, o cumaru (Amburana cearensis) foi a espécie que contém a maior quantidade de extrativos em sua madeira e, no entanto, foi uma das mais atacadas pelos térmitas testados.

Para as espécies testadas, o cerne apresenta maior teor de extrativos que o alburno, exceção feita para o cumaru, em que a água fria extraiu uma quantidade numericamente maior de substâncias do alburno.

As madeiras com maior quantidade de cinzas apresentaram maior resistência ao ataque dos cupins.

Para as espécies testadas, a madeira de angico foi a mais resistente e a de eucalipto a menos resistente ao ataque de térmitas, tanto o cerne quanto o alburno.

Dentre as espécies nativas da Caatinga testadas, o cumaru demonstrou menor resistência aos cupins e a craibeira resistência intermediária entre o angico e o cumaru.

\section{REFERÊNCIAS}

AMERICAN SOCIETY FOR TESTING AND MATERIALS. Annual book of ASTM standards. Philadelphia, 2005. 608 p.

FINDLAY, W. P. K. The nature and durability of wood. In: Preservation of timber in the tropics. Dordrecht: M. Nijhoff, 1985. p. 1-13.

MORI, C. L. S. O.; MORI, F. A.; MENDES, L. M.; SILVA, J. R. M. Caracterização da madeira de angico-vermelho (Anadenanthera peregrina (Benth.) Speng.) para confecção de móveis. Brasil Florestal, Brasília, v. 23, n. 77, p. 29-36, 2003. 
OLIVEIRA, J. T. S.; SOUSA, L. C.; DELLA LUCIA, R. M.; SOUSA JÚNIOR, W. P. Influencia dos extrativos na resistência ao apodrecimento de seis espécies de madeira. Revista Árvore, Viçosa, v. 29, n. 5, p. 819-826, set./out. 2005.

PAES, J. B.; LIMA, C. R.; MORAIS, V. M. Resistência natural das madeiras de angico (Piptadenia macrocarpa), cumaru (Amburana cearensis) e pereiro (Aspidosperma pyrifolium) a fungos e cupins xilófagos, em condições de laboratório. Brasil Florestal, Brasília, v. 22, n. 75, p. 45-52, 2003.

PAES, J. B.; LIMA, C. R.; OLIVEIRA, E.; MELO, R. R. Resistência natural de sete madeiras ao cupim subterrâneo (Nasutitermes corniger Motsch.) em ensaio de preferência alimentar. Revista Brasileira de Ciências Agrárias, Recife, v. 2, n. 1, p. 57-62, 2007.

PAES, J. B.; MORAIS, V. M.; LIMA, C. R. Resistência natural de nove madeiras do Semi-árido brasileiro a cupins subterrâneos, em ensaio de preferência alimentar. Brasil Florestal, Brasília, v. 20, n. 72, p. 59-69, 2001.
PANSHIN, A. J.; ZEEUW, C. de. Textbook of wood technology. $4^{\text {th }}$ ed. New York: McGraw-Will, 1980. 722 p.

PETTERSEN, R. C. Chemical composition of wood. In: ROWELL, R. (Ed.). The chemistry of solid wood. Washington: American Chemical Society, 1984. p. 54-126.

SCHEFFER, T. C. Microbiological deterioration and its casual organisms. In: NICHOLAS, D. D. (Ed.). Wood deterioration and its prevention treatments: degradation and protection of wood. Syracuse: Syracuse University, 1973. v. 2, p. 31-106.

SILVÉRIO, F. O.; BARBOSA, L. C. A.; GOMIDE, J. L.; REIS, F. P.; VELOSO, D. P. Metodologia de extração e determinação do teor de extrativos em madeiras de eucalipto. Revista Árvore, Viçosa, v. 30, n. 6, p. 109-116, nov./dez. 2006.

STEEL, R. G. D.; TORRIE, J. H. Principles and procedures of statistic: a biometrical approach. $2^{\text {nd }}$ ed. New York: McGraw-Hill, 1980. 633 p.

Recebido: 3 de junho de 2011; aceito: 20 de dezembro de 2012.

Cerne, Lavras, v. 19, n. 3, p. 399-405, jul./set. 2013 
